\title{
Green Preparation of Citric Acid Crosslinked Starch for Improvement of Physicochemical Properties of Cyperus Starch
}

\section{Cyperus Nişastasının Fizikokimyasal Özelliklerinin İyileştirilmesi için Sitrik Asit Çapraz Bağlanmış Nişastanın Yeşil Hazırlanması}

\author{
(D) Bunmi OLAYEMI ${ }^{1 *}$, (D) Christianah Yetunde ISIMI1 , (D) Kokonne EKERE1, (D) Ajeh JOHNSON ISAAC1, (D) Judith Eloyi OKOH¹, (D) Martins EMEJE2 \\ ${ }^{1}$ National Institute for Pharmaceutical Research and Development (NIPRD), Department of Pharmaceutical Technology and Raw Materials Development, \\ Abuja, Nigeria \\ 2National Institute for Pharmaceutical Research and Development (NIPRD), Centre for Nanomedicine and Biophysical Drug Delivery, Abuja, Nigeria
}

\section{ABSTRACT}

Objectives: This study was undertaken to assess the properties of Cyperus esculentus tuber starch crosslinked with citric acid from liquid substrates of orange peel derived via the natural solid-state fermentation process; a green approach.

Materials and Methods: The flow properties of the prepared starches were evaluated using standard methods. Water-holding capacity, swelling capacity, moisture sorption capacity, gelatinization temperature using differential scanning calorimetry, morphology, fourier infrared spectroscopy, and $\mathrm{pH}$ of the starches were evaluated.

Results: Results showed that the pH of the crosslinked starches were lower (3.39-4.07) than that of the native starch (5.25) and the flow profile was found to improve. The crosslinked starches' water-holding capacity (90.67\%-96.69\%) were higher, whereas its emulsion capacity (15.33) was similar to that of the native starch (15.33). No change was observed in the morphology of the crosslinked starches' granules. The infrared spectra of the native and crosslinked starches showed identical peaks; however, the enthalpy of gelatinization ( $\Delta$ Hgel) of the crosslinked products were found to differ from that of the native starch. Modified starches show propensity of being exploited as binding agents in food and pharmaceutical industries.

Conclusion: The green modification process proved to be a valuable addition to the available starch modification processes.

Key words: Cyperus esculentus tuber starch, crosslinking, citric acid, orange peel, crosslinked starch

\section{ÖZ}

Amaç: Bu çalışma yeşil bir yaklaşımla, doğal katı hal fermantasyon işlemi yoluyla portakal kabuğunun sıvı substratlarından elde edilen sitrik asit ile çapraz bağlanan Cyperus esculentus yumru nişastasının özelliklerini değerlendirmek için yapılmıştır.

Gereç ve Yöntemler: Hazırlanan nişastaların akış özellikleri standart yöntemler kullanılarak değerlendirildi. Nişastaların su tutma kapasitesi, şişme kapasitesi, nem tutma kapasitesi, jelatinleștirme sıcaklığı, diferansiyel tarama kalorimetresi kullanılarak morfolojisi, fourier kızılötesi spektroskopisi kullanılarak değerlendirildi ayrıca pH'leri belirlendi.

Bulgular: Bulgular, çapraz bağlı nişastaların pH'nin, doğal nişastanın $(5,25)$ pH'sinden daha düşük olduğunu $(3,39-4,07)$ ve akış profilinin iyileștiğini gösterdi. Çapraz bağlanmış nişastaların su tutma kapasitesi $(\% 90,67-\% 96,69)$ daha yüksekti, oysa emülsiyon kapasitesi $(15,33)$ doğal nişastanınkine $(15,33)$ benziyordu. Çapraz bağlanmış nişasta granüllerinin morfolojisinde hiçbir değişiklik gözlenmedi. Doğal ve çapraz bağlı nişastaların kızı̈ötesi spektrumları özdeş zirveler gösterdi; bununla birlikte çapraz bağlanmış ürünlerin jelatinleşme entalpisinin ( $\Delta$ Hgel) doğal nişastanınkinden farklı olduğu bulunmuştur. Değiştirilmiş nişastalar, gıda ve ilaç endüstrilerinde bağlayıcı maddeler olarak sömürülme eğilimi gösterir.

Sonuç: Yeşil modifikasyon prosesinin, mevcut nişasta modifikasyon proseslerine katkı sağlayacağı kanıtlandı.

Anahtar kelimeler: Cyperus esculentus yumru nişastası, çapraz bağlama, sitrik asit, portakal kabuğu, çapraz bağı nişasta

*Correspondence: olubunmibiala@yahoo.co.uk, Phone: +2348033532299 ORCID-ID: orcid.org/0000-0001-5759-7176

Received: 13.09.2019, Accepted: 05.12.2019

๑Turk J Pharm Sci, Published by Galenos Publishing House. 


\section{INTRODUCTION}

Starch has been widely sourced from plant roots, seeds, leaves, and fruits in recent past, however, modern trends in technologies and processes have moved on to adopt other sources in obtaining starch. In the development of starch, nonconventional sources with wide applicability in pharmaceutical formulations as tablet binders and disintegrants, glidants, suspending, and emulsifying agents have been exploited. ${ }^{1-6}$

Although starch in its native form has many potentials, its poor flow properties, instability when exposed to high temperature and under high shear rate, variations in $\mathrm{pH}$, high retrogradation, its limited solubility in common organic solvents, and freezethaw processes make them less desirable for industrial applications..$^{7-9}$ Therefore, to find means of overcoming these limitations while developing versatile starch-based excipients that have multifunctional applications is the goal of many formulation scientists. One solution to this demanding technological need is to modify native starch properties. This involves tweaking its physical and chemical characteristics to improve its functionality with useful structural attributes via physical, chemical, enzymatic, and genetic means. ${ }^{10-13}$

In the last century, the most prevalent means employed in modifying starch was chemical modification, and the developed products have found several applications in the food, textile, and pharmaceutical industries. ${ }^{14}$ This type of adaptation involves the incorporation of functional groups through chemical reactions that can alter the starch molecule or substitute some functional groups. However, the modification outcome is influenced by factors like starch source, reactant type, reaction concentration and time, and the reacting medium's $\mathrm{pH}$. Chemical modification through etherification, esterification, decomposition, grafting, and crosslinking techniques yields starch products. ${ }^{12}$

A covalent interconnection is introduced by crosslinking through hydrogen bonds in starch granules, which provides strong bonds between molecules and restrict polymer chain movement. ${ }^{15,16}$ This decreases the rate of starch retrogradation, which consequently increases its gel rigidity and hardness, in addition to enhancing its solubility in organic solvents..$^{8,17}$

In the crosslinking reaction, various reagents are used, which determines the property of the crosslinked product. Hirsch and Kokini ${ }^{18}$ showed that the reaction of waxy maize starch with phosphorous oxychloride produced starch with high viscosity and minimum swelling. In Wattanachanta et al. ${ }^{19}$ crosslinking sago starch with a mixture of sodium trimetaphosphate and sodium tripolyphosphate (STPP) produced starch with high resistance to acids, rigid gels, and high freeze-thaw stability. The reaction of chlorinated corn starch with formaldehyde was investigated in another study and it was observed that increasing the quantity of formaldehyde while reducing oxidation extent improved the reaction process' efficiency and the products. ${ }^{20}$

In a completely different study, Chowdary and Chaithanya ${ }^{21}$ found that the product was insoluble in aqueous, alkaline, and acidic media, the process of crosslinking potato starch gelatinized with urea imparted better flow on the starch.
However, prolonged drug release for up to $24 \mathrm{~h}$ was observed in the tablet formulations produced by the crosslinked starch; thus concluding that the product could be used in the preparation of extended-release tablet formulations.

The crosslinking effect of the Icacina trichantha tuber starch was investigated by Omojola et al. ${ }^{7}$ and they observed that water absorption capacity in the modified starch was higher than in the native starch, with no gelatinization occurring upon heating. They proposed that the modified starch could be a more effective tablet disintegrant than the native I. trichantha tuber starch. In another study by Omojola et al. ${ }^{22}$ the reaction of Cola nitida starch with acetic anhydride and STPP as explored, and results showed lower viscosity, solubility, and swelling in the obtained crosslinked starch than in the unreacted starch, and was thus suggested for use as a food thickener.

Isah et al. ${ }^{9}$ reported that Digitaria exilis starch crosslinked with citric acid decreases the oil and water absorption capacities, foam capacity, and $\mathrm{pH}$ of the modified starch. By using scanning electron microscopy, they observed that the starch granule's shape and morphology were not altered by crosslinking; whereas the presence of an additional peak was shown using fourier transform infrared (FTIR). This suggested the use of the crosslinked $D$. exilis starch in the food and pharmaceutical industry.

In the crosslinking process, agents like citric acid have been commonly used. Citric acid is a very essential organic acid that is widely utilized in the food and pharmaceutical industries. It is an intermediate of the tricarboxylic acid cycle, and is found in a variety of acidic fruit juices, particularly the citrus family. ${ }^{23}$ Citrus fruits are readily available in most regions of the world. Annually, after the extraction of the citrus juice, processing industries generate tons of residues, including peels and segment membranes, for commercial purposes. However, these wastes are usually not put to use/reasonable use, thus creating environmental hazards. For example, the burden already present at landfills where solid wastes are deposited is increased; whereas liquid wastes disposed into the rivers could cause nutrient imbalance, loss of oxygen, and, consequently, death of the aquatic life. Failure to exploit these wastes' potential could also impact negatively on the economy. Citric acid, with an estimated annual production of about $10,000,000$ tons, has one of the highest level of production worldwide among fermentation products. ${ }^{24}$

In recent years, various manufacturing processes and products with marginal likelihood of causing harm have been explored by researchers and scientists while also improving the sustainability of product development.25,26 This can be achievable through the green approach system, which, in addition to reducing waste, entails manufacturing processes that create technologies that are safer for the environment and those working in those environment. Innovations through green synthesis has led to the development of diverse products for different applications, including the production of citric acid by fermentation of citrus byproducts using microorganisms. ${ }^{27,28}$

Submerged, surface, and solid-state are the different techniques employed in the production of citric acid through fermentation, with the latter being the simplest of all the techniques. ${ }^{29,30}$ 
To obtain citric acid from fruit wastes, we intend to use the green approach, which would serve as a precursor for the development of a pharmaceutical excipient. Therefore, this study aims to crosslink starch obtained from Cyperus esculentus seed using liquid substrates of orange peel derived by means of the natural solid-state fermentation process, and evaluate its physiochemical properties.

\section{MATERIALS AND METHODS}

\section{Materials}

Tigernut starch (TS) from C. esculentus tuber [extracted from the Department of Pharmaceutical Technology and Raw Material Development, National Institute for Pharmaceutical Research and Development (NIPRD), Abuja, Nigeria] and oranges (obtained from Karmo market, Abuja, Nigeria).

\section{Orange peel substrate preparation}

Fresh oranges were procured from the Karmo market in Abuja. They were washed with water, and the skin was separated from the fruit's pulpy segments. Orange peel of $900 \mathrm{~g}$ was soaked in $2.5 \mathrm{~L}$ of water, and the mixture's $\mathrm{pH}$ was recorded. The soaked peels' $\mathrm{pH}$ was subsequently recorded on days 1, 5, and 15.

\section{Starch preparation}

The method of Kunle et al. ${ }^{31}$ was used to extract the TS.

\section{Preparation of modified starch}

The procedure described earlier ${ }^{32}$ was adopted with some modifications. On day 5 , the orange peel substrate's $\mathrm{pH}$ was determined, and $50 \mathrm{~mL}$ of the filtered substrate was poured in a beaker. Placed in another beaker was $50 \mathrm{~g} \mathrm{TS}$, where the filtered substrate was then added in aliquots and mixed until a smooth paste was obtained. The resulting paste was spread on a tray and left to dry at room temperature for about $18 \mathrm{~h}$. The air-dried product was then oven-dried at $60^{\circ} \mathrm{C}$ for $1 \mathrm{~h}$ and 30 min. Using a mortar and pestle, the oven-dried product was size-reduced and after which it was further dried in the oven for $2 \mathrm{~h}$ at $130^{\circ} \mathrm{C}$. The product (TS1) was then cooled, weighed, and then stored in the desiccator for further analysis.

Other products of the modified starch (TS2 and TS3) were prepared according to the procedure previously stated using orange peel substrate obtained on days 10 for TS2 and 15 for TS3.

\section{Physicochemical properties evaluation of the modified starch}

\section{Morphology}

Under a light microscope (Leica DM light microscope) at a magnification x400, a small quantity of TS was mounted on the microscope slide and was examined. The starch product's shape was extrapolated from the photomicrograph.

\section{pH determination}

The $\mathrm{pH}$ of a $10 \% \mathrm{w} / \mathrm{v}$ slurry of the starch product was determined at room temperature $\left(28^{\circ} \mathrm{C}\right)$ using the $\mathrm{pH}$ meter. Triplicate determinations were made and the mean was computed.

\section{Angle of repos}

The funnel method was used; $20 \mathrm{~g}$ each of the dried products (TS0, TS1, TS2, and TS3) was allowed to flow through a funnel clamped at a fixed height from a flat surface. The powder heap's height $(h)$ and radius $(r)$ were measured, and the repose angle (A) was calculated as follows,

$A=\tan -1 \mathrm{~h} / \mathrm{r}$.

\section{Bulk and tapped densities}

In a graduated cylinder, the volume occupied by the $20 \mathrm{~g}$ starch product was noted; and the bulk density $(\mathrm{g} / \mathrm{mL})$ was calculated as the ratio of the powder's weight to the volume occupied in the cylinder. Similarly, the tapped density $(\mathrm{g} / \mathrm{mL})$ was computed as the ratio of the powder's weight to the volume it occupied after tapping the cylinder 100 times.

\section{Carr's compressibility index $(\mathrm{Cl})$ and Hausner ratio (HR)}

Carr's $\mathrm{Cl}, \%$ ) was calculated as follows:

(tapped density-bulk density)/(tapped density) x 100 .

HR was computed as the ratio between the tapped and bulk densities.

\section{Swelling capacity}

A slurry of the starch product ( $1 \% \mathrm{w} / \mathrm{v})$ was made in distilled water. With intermittent stirring, the dispersion was heated on a water bath (Karl kolb, Dreiech West Germany) at $30^{\circ} \mathrm{C}$ for $30 \mathrm{~min}$. This was then centrifuged at $1500 \mathrm{rpm}$ for $30 \mathrm{~min}$; the supernatant was discarded, the starch paste weight was determined, and the swelling capacity was calculated as follows:

$\mathrm{S}(\%)=$ (weight of wet starch)/(initial weight of dry starch) $\times 100$.

This procedure was carried out for each of the starch products (TSO, TS1, TS2, and TS3) at $30^{\circ} \mathrm{C}, 40^{\circ} \mathrm{C}, 50^{\circ} \mathrm{C}, 60^{\circ} \mathrm{C}, 70^{\circ} \mathrm{C}, 80^{\circ} \mathrm{C}$, and $90^{\circ} \mathrm{C}$.

\section{Gelatinization temperature}

Differential scanning calorimetry (DSC) was used to determine the gelatinization temperature. The starch samples $(5 \mathrm{mg})$ were placed in an aluminum pan, and a drop of water was added. At a heating rate of $10^{\circ} \mathrm{C}$ under constant nitrogen flow, the samples were scanned between $60^{\circ} \mathrm{C}$ and $300^{\circ} \mathrm{C}$.

\section{Water-holding capacity}

To obtain the water-holding capacity, the method of Kornblum and Stoopak ${ }^{33}$ was adopted. The crosslinked starch dispersion $(1 \% \mathrm{w} / \mathrm{v})$ was placed in preweighed, stoppered centrifuge tube and shaken intermittently for $10 \mathrm{~min}$ and was left to stand for another $10 \mathrm{~min}$. It was then centrifuged at 1,500 rpm for $5 \mathrm{~min}$; the supernatant was discarded and the weight of the hydrated starch was determined. Hydration capacity was calculated using the equation below,

$H(\%)=$ (weight of dry starch)/(weight of starch sediment $\times 100$ ).

\section{Foam capacity}

For foam capacity, the method by Isah et al. ${ }^{9}$ was adopted. The starch product's water dispersion of $2 \% \mathrm{w} / \mathrm{v}$ was homogenized for $5 \mathrm{~min}$. It was poured into a measuring cylinder $(50 \mathrm{~mL})$, and the volume was recorded after $30 \mathrm{~s}$. The percentage increase in volume expressed is the foam capacity. 


\section{Emulsion capacity}

Emulsion capacity was also carried out based on the method of Isah et al. ${ }^{9}$ The starch product was dispersed in water $(2 \% \mathrm{w} / \mathrm{v})$ and homogenized for $2 \mathrm{~min}$. After which, vegetable oil ( $2.5 \mathrm{~mL})$ was gradually added to the mixture and stirred continuously for $30 \mathrm{sec}$. The suspension was centrifuged at 1,600 rpm for $5 \mathrm{~min}$, and the volume of oil floating was determined. The computed quantity of oil emulsified per gram of the sample is the emulsion capacity.

\section{Moisture content}

The oven-dry method was used to determine moisture content. The starch product $(0.5 \mathrm{~g})$ was placed into a dry crucible $\left(\mathrm{W}_{1}\right)$ and was placed in an oven at for $10-12 \mathrm{~h}$ at $100-105^{\circ} \mathrm{C}$ until constant weight was obtained. The crucible was then allowed to cool in a desiccator for $30 \mathrm{~min}$ and was reweighed $\left(\mathrm{W}_{2}\right)$. Moisture content (\%) was calculated as follows:

$\mathrm{W}_{1}-\mathrm{W}_{2} / \mathrm{W}_{1} \times 100$.

\section{Moisture sorption capacity}

The starch product $(1 \mathrm{~g})$ was placed in a tarred porcelain dish and was weighed $\left(\mathrm{W}_{1}\right)$. The dish was then placed in a desiccator containing distilled water. The sample and dish were weighed daily $\left(W_{2}\right)$ for 5 days, and the moisture sorption capacity was determined as follows,

$\mathrm{W}_{1}-\mathrm{W}_{2} / \mathrm{W}_{1} \times 100$.

\section{FTIR spectral studies}

Native TS and the crosslinked products (TS1, TS2, and TS3) were triturated with potassium bromide and were made into pellets $\left(1 \mathrm{ton} / \mathrm{cm}^{2}\right)$. The Nicolet iS10, Thermo Scientific (USA), FTIR spectrometer was used to take the IR spectra between the scanning ranges of 4,000 and $400 \mathrm{~cm}^{-1}$.

\section{Statistical analysis}

Results were obtained from at least three determination and were expressed as mean \pm standard deviation.

\section{RESULTS AND DISCUSSION}

\section{Organoleptic properties of TS and its crosslinked derivatives}

Table 1 shows the organoleptic properties of TS and its crosslinked products. Native TS (TSO) was a white, tasteless, and odorless smooth powder, whereas the crosslinked productsthat had been reacted with orange peel substrates from days 5 (TS1), 10 (TS2), and 15 (TS3) were observed to be off-white in color, odorless with a characteristic taste, and is coarse to touch. The color change observed in the crosslinked products can be attributed to the color of the orange peel substrate used.

\section{pH of orange peel substrate}

Table 2 presents the $\mathrm{pH}$ of the orange peel substrate on days $0,5,10$, and 15 . Results show that during the study period, the substrate's pH was not consistent; the pH decreased to 2.00 by day 5 and increased to 2.79 by day 10 but decreased again to 2.30 by day 15 . This could be a result of fermentation where microorganisms use carbohydrates from the substrate as a source of energy, thus influencing the substrate/medium's chemical environment. This process causes lactobacillus growth, which produce organic acids that lowers the medium's $\mathrm{pH}$. The absence of a trend in the substrate's $\mathrm{pH}$ could be associated with the fact that microorganisms consumed the nutrients from the orange peels at the beginning fo the fermentation process and released organic acids into the medium, thus lowering the $\mathrm{pH}$; however, shortage of these nutrients after a period of time could have resulted in the consumption of the organic acids, which led to an increase in the medium's pH. Because the initial decrease in $\mathrm{pH}$ is attributed to citric acid production, it implies that the crosslinking effect on starch products treated with substrate on day 5 (TS1) would be greater than that on day 10 (TS2) when the $\mathrm{pH}$ was observed to increase again. Factors that influence the medium's pH kinetics are the substrates' nature in the fermentation medium and the method by which the organic acids are produced. ${ }^{34}$

\section{Flow properties of TS and its crosslinked derivatives}

Flow properties results of TS products (TS0, TS1, TS2, and TS3) are shown in Table 3. A material's repose angle is a reflection of its flow ability; values less than $30^{\circ}$ are an indication of excellent flow, whereas those between $31^{\circ}$ and $35^{\circ}, 36^{\circ}$ and $40^{\circ}$, and those greater than $40^{\circ}$ are indicative of good, fair, and poor flow, respectively..$^{35}$ Obtained values for TSO $\left(33.06^{\circ}\right.$ ) and TS1 $\left(34.66^{\circ}\right)$ were observed to be similar, showing that they possess good flow; whereas TS2 $\left(26.96^{\circ}\right)$ and TS3 $\left(30.39^{\circ}\right)$ were lower, which reveal that they have good to excellent flow ability.

\begin{tabular}{ll} 
Table 2. pH of orange peel substrate & \\
\hline Day & $\mathrm{pH}$ \\
\hline 0 & $5.23 \pm 0.05$ \\
\hline 5 & $2.00 \pm 0.02$ \\
\hline 10 & $2.79 \pm 0.01$ \\
\hline 15 & $2.30 \pm 0.02$ \\
\hline
\end{tabular}

Number of determinations $(n)=3, \pm$ standard deviation

Table 1. Organoleptic properties of Tigernut starch products (TSO, TS1, TS2, and TS3)

\begin{tabular}{lllll} 
Parameters & TS0 & TS1 & TS2 & TS3 \\
\hline Color & White & Off-white & Off-white & Off-white \\
\hline Odor & Odorless & Characteristic & Characteristic & Characteristic \\
\hline Taste & Tasteless & Bland & Bland & Bland \\
\hline Texture & Smooth & Coarse & Coarse & Coarse \\
\hline
\end{tabular}

Number of determinations $(n)=6$, TS: Tigernut starch 
An increase in citric acid probably resulted in better modification as a substitution result of more $\mathrm{OH}$ groups on starch, leading to a less amorphous and better flowing product. Carr's $\mathrm{Cl}$ is a parameter that assesses a material's ability to deform under pressure; whereas HR measures powdered material's cohesiveness by determining that material'sthe densification degree. ${ }^{35}$ A material has excellent, moderate, or fair flow when $\mathrm{Cl} \leq 10 \%, \mathrm{Cl}$ : $16 \%-20 \%$, or $\mathrm{Cl}$ : $21 \%-25 \%$, respectively. Consequently, the material is cohesive when $\mathrm{HR} \leq 1.11$, and become less cohesive when values are between 1.12 and 1.2.

The results presented in Table 3 show that increasing the fermentation period improved the flow of the crosslinked starch products (TS1, TS2, and TS3), with TS3 having lower $\mathrm{Cl}(25.24 \%)$ and $\mathrm{HR}(1.34)$ than TS2 (Cl, 29.24\%; HR, 1.42) and TS1 ( $\mathrm{Cl}, 30.36 \% ; \mathrm{HR}, 1.45)$. Moreover, these values were also observed to be lower than those obtained for native starch (32.13\% and 1.47), indicating that treating the starch with the orange peel substrate improved the flow of TS.

This indicates that when pressure is applied during tablet compression, the crosslinked starch (TS3) would produce good compacts. It also shows that there would be reproducible product manufacture and performance with consequent uniform drug distribution in the tablet batch.

Physicochemical properties of TS and its crosslinked derivatives The $\mathrm{pH}$ of native TS (TSO, 5.25) was similar to that reported (5.60) by Kenneth et al. ${ }^{36}$ in their characterization of TS. For the crosslinked products (TS1, TS2, and TS3), the values obtained were found to be lower $(4.07,3.39$, and 3.87, respectively) and could be linked to the varying $\mathrm{pH}$ of orange peel substrate used. This may also be attributed to the presence of carboxylic acid on the starch molecule leading to increased acidity.

However, these values were within the range (3-9) specified for most starches used in pharmaceutical, cosmetics, and food industries. ${ }^{37}$ This result is also similar to some earlier reports ${ }^{7,34}$ where the $\mathrm{pH}$ of $I$. trichantha tuber starch and Tacca involucrate tuber starch crosslinked with citric were found to be 4.59 and 4.68 , respectively. In addition, pastes from various modified starches have been documented to be acidic, therefore, the results of this study is consistent with earlier reports. ${ }^{38-40}$

Presented in Table 4 are the water-holding capacities of TS products. The crosslinked products' water-holding capacity (TS1, TS2, and TS3) were observed to increase with the orange peel substrate's length of stay. They were also found to be appreciable $(91.37 \%, 90.37 \%$, and $96.69 \%$, respectively) compared with the native starch TSO (85.55\%). Water-holding capacity is a material's capacity to retain water when pressure is applied or when heated; it is also the measure of that material's hydration capacity. ${ }^{41}$ The observed increase in water-holding capacity may be ascribed the carboxyl groups' attachment on the starch molecules, thus, improving its ability to imbibe water. Specifically in the application of starch products as disintegrants in solid dosage formulations or as drug carriers for controlled drug delivery systems, this phenomenon is desirable. ${ }^{39}$ This result is in tandem with those of Icacina and Tacca starch citrate. ${ }^{7,32}$ In Jyothi et al., ${ }^{42}$ cassava starch citrate was also reported to have higher water-holding ability than the native cassava starch.

Foam and emulsion capacities are vital functional properties that determine the behavior and applicability of these starches in processing, consumption, and storage. The crosslinked products' foam capacity were observed to be the same (3.33) but slightly higher than that of the native starch (3.07). On the other hand, their emulsion capacities were found to be the same $(15.33 \%)$, indicating that their emulsifying property was not affected by starch modification. These results demonstrate the modified starches' ability (TS1, TS2, and TS3) to decrease

Table 3. Flow properties of Tigernut starch products (TS0, TS1, TS2, and TS3)

\begin{tabular}{lllll} 
Parameters & TS0 & TS1 & TS2 & TS3 \\
\hline Angle of repose $\left({ }^{\circ}\right)$ & $33.06 \pm 1.79$ & $34.66 \pm 1.05$ & $30.39 \pm 1.01$ & $26.96 \pm 1.02$ \\
\hline Bulk density $(\mathrm{g} / \mathrm{mL})$ & $0.46 \pm 0.01$ & $0.49 \pm 0.01$ & $0.48 \pm 0.01$ & $0.50 \pm 0.01$ \\
\hline Tapped density $(\mathrm{g} / \mathrm{mL})$ & $0.68 \pm 0.01$ & $0.71 \pm 0.02$ & $0.68 \pm 0.01$ & $0.67 \pm 0.01$ \\
\hline Hausner ratio & $1.47 \pm 0.02$ & $1.45 \pm 0.01$ & $1.42 \pm 0.04$ & $1.34 \pm 0.03$ \\
\hline Carr's index $(\%)$ & $32.18 \pm 1.03$ & $30.36 \pm 1.57$ & $29.24 \pm 2.06$ & $24.25 \pm 1.30$ \\
\hline
\end{tabular}

Number of determinations $(n)=3, \pm$ standard deviation, TS: Tigernut starch

Table 4. Physicochemical properties of Tigernut starch products (TS0, TS1, TS2, and TS3)

\begin{tabular}{lllcc} 
Parameters & TS0 & TS1 & TS2 & TS3 \\
\hline $\mathrm{pH}$ & $5.25 \pm 0.02$ & $4.07 \pm 0.02$ & $3.39 \pm 0.06$ & $3.87 \pm 0.02$ \\
\hline Water-holding capacity (\%) & $85.55 \pm 1.05$ & $91.37 \pm 5.42$ & $90.67 \pm 3.40$ & $96.69 \pm 1.88$ \\
\hline Foam capacity (\%) & $3.07 \pm 1.01$ & $3.33 \pm 1.15$ & $3.33 \pm 1.15$ & $3.33 \pm 1.15$ \\
\hline Emulsion capacity (\%) & $15.33 \pm 0.58$ & $15.33 \pm 0.58$ & $15.33 \pm 0.58$ & $15.33 \pm 0.58$ \\
\hline Moisture content (\%) & $8.00 \pm 0.30$ & $7.80 \pm 0.10$ & $8.10 \pm 0.10$ & $9.20 \pm 1.00$ \\
\hline Moisture sorption capacity (\%) & 5.87 & 5.42 & 5.84 & 5.54 \\
\hline
\end{tabular}

Number of determinations $(n)=3, \pm$ standard deviation, TS: Tigernut starch 
surface tension, and as such may be used as emulsifiers in food, cosmetic, and pharmaceutical products.

The crosslinked starches' moisture content increased with the increase of the crosslinking substrate's concentration $(7.8 \%$, $8.1 \%$, and $9.2 \%$, respectively) and were generally comparable with that of the native starch ( $8 \%)$. These values are within the limit specified for pharmaceutical starches ${ }^{43}$ as presence of excessive moisture can impact negatively on the flow and mechanical properties of the material. ${ }^{44}$ In addition, it can promote microorganism growth in the formulation during packaging and storage and decrease the formulation's stability and shelf-life. ${ }^{45}$

Moisture sorption capacity is a measure of moisture sensitivity and an indication of a material's physical stability under storage. ${ }^{46}$ The crosslinked starches showed similar sorption capabilities $(5.42 \%, 5.84 \%$, and $5.54 \%$, respectively) with the native starch (5.87\%). Materials with low values less tendency to undergo hydrolytic degradation, thus, are beneficial in formulations containing moisture-sensitive drug components.

Table 5 shows the swelling capacity of TSO, TS1, TS2, and TS3 over a range of temperatures $\left(30^{\circ} \mathrm{C}-90^{\circ} \mathrm{C}\right)$. Starch granules' ability to absorb water when exposed to heat is portrayed by its swelling characteristics. Swelling over different temperature ranges is important because it evaluates the starches' behavior under industrial conditions. Although swelling was found to be higher at higher temperatures $\left(60^{\circ} \mathrm{C}-90^{\circ} \mathrm{C}\right)$ than at lower temperatures $\left(30^{\circ} \mathrm{C}-50^{\circ} \mathrm{C}\right.$ ), the results show a general increase in starch volume as the exposure temperature increased for the native and crosslinked starches. This pattern is ascribed to intrinsic binding forces that tend to weaken at varying temperatures, ${ }^{47}$ and as reported by Omojola et al. ${ }^{48}$ However, an exception to this trend was observed with TS2, where swelling was observed to appreciably increase at $80^{\circ} \mathrm{C}$ but decreased at $90^{\circ} \mathrm{C}$. TS1, TS2, and TS3 showed similar swelling patterns at $30^{\circ} \mathrm{C}, 40^{\circ} \mathrm{C}, 50^{\circ} \mathrm{C}$, and $60^{\circ} \mathrm{C}$. However, less swelling was observed in TS2 at $70^{\circ} \mathrm{C}$ than TS1 and TS3; at $90^{\circ} \mathrm{C}$, no further swelling was observed in TS2 and TS3. Of all the starches, TS1's swelling profile was observed to be the most consistent (progressively increasing).

\begin{tabular}{lllll}
$\begin{array}{l}\text { Table 5. Swelling power Tigernut starch products (TS0, TS1, TS2, } \\
\text { and TS3) }\end{array}$ & TS1 & TS2 & TS3 \\
$\begin{array}{l}\text { Temperature } \\
{ }^{\circ} \mathrm{C} \text { ) }\end{array}$ & TS0 & TS1 & $2.09 \pm 0.07$ & $2.55 \pm 0.03$ \\
\hline 30 & $2.33 \pm 0.43$ & $2.38 \pm 0.11$ & $2.09 .17 \pm 0.43$ \\
\hline 40 & $2.52 \pm 0.11$ & $2.79 \pm 0.09$ & $2.64 \pm 0.17$ & $2.70 \pm 0.43 \pm 0.09$ \\
\hline 50 & $2.44 \pm 0.19$ & $2.43 \pm 0.17$ & $2.22 \pm 0.04$ & $2.63 \pm 0.09$ \\
\hline 60 & $2.68 \pm 0.13$ & $2.69 \pm 0.05$ & $2.54 \pm 0.17$ & $2.97 \pm 0.17$ \\
\hline 70 & $5.59 \pm 0.40$ & $5.53 \pm 0.14$ & $3.56 \pm 0.10$ & $5.22 \pm 0.42$ \\
\hline 80 & $8.77 \pm 0.93$ & $8.03 \pm 0.08$ & $8.00 \pm 0.30$ & $8.03 \pm 0.11$ \\
\hline 90 & $7.44 \pm 0.34$ & $9.18 \pm 0.76$ & $7.35 \pm 0.24$ & $8.01 \pm 0.17$ \\
\hline
\end{tabular}

Number of determinations $(n)=3, \pm$ standard deviation, TS: Tigernut starch
Nonetheless, the swelling profile of the native and crosslinked starches were similar. This suggests that crosslinking did not have any effect on granule swelling and could be attributed to increased resistance to starch granule swelling because of higher bond strength conferred by crosslinking, which has also been reported by Xie and Liu. ${ }^{49}$

These starches may not be good disintegrant candidates for solid dosage formulations because of their limited water uptake into starch granules, which implies that structural granule break down will not take place. However, our result is different from those of Adebiyi et al., ${ }^{32}$ where Tacca starch citrate was observed to have higher swelling power than that of the native Tacca starch. This can be attributed to differences in the biological sources of starch materials and starch extraction methods employed.

Figure 1 illustrates the morphology of the native and crosslinked starches. The native starch (TSO) have small and large-sized, oval-shaped, smooth granules occurring mostly in single unaggregated forms. The crosslinked starches (TS1, TS2, and TS3) are more uniform in size, oval-shaped, and occur in aggregates that are observed to increase with the time of crosslinking (TS1 > TS2 > TS3). Here, application of the orange peel substrate to modify TS did not rupture or change the granule morphology, which shows that under applied pressure resulting in higher bond strength, modified starch would pack more closely and consolidate better than the native starch. Starch granules with small and uniform sizes are widely used in pharmaceutical and food industries, ${ }^{50}$ as such, this cheap substrate crosslinked starches could find application in these industries.

\section{FTIR of TS and its crosslinked derivatives}

Figure 2 presents the FTIR spectra of the starch products. The native starch shows significant peaks at $3240 \mathrm{~cm}^{-1}$, whereas those of TS1, TS2, and TS3 are 3257.7, 3235.3, and $3250.2 \mathrm{~cm}^{1}$, respectively, all indicating $\mathrm{OH}$ stretching. The band $2929.7 \mathrm{~cm}^{-1}$ of the native starch is characteristic of $\mathrm{C}-\mathrm{H}$ stretches associated with ring hydrogen atoms and was observed to slightly decrease to $2926 \mathrm{~cm}^{-1}$ in all the crosslinked products. The change in
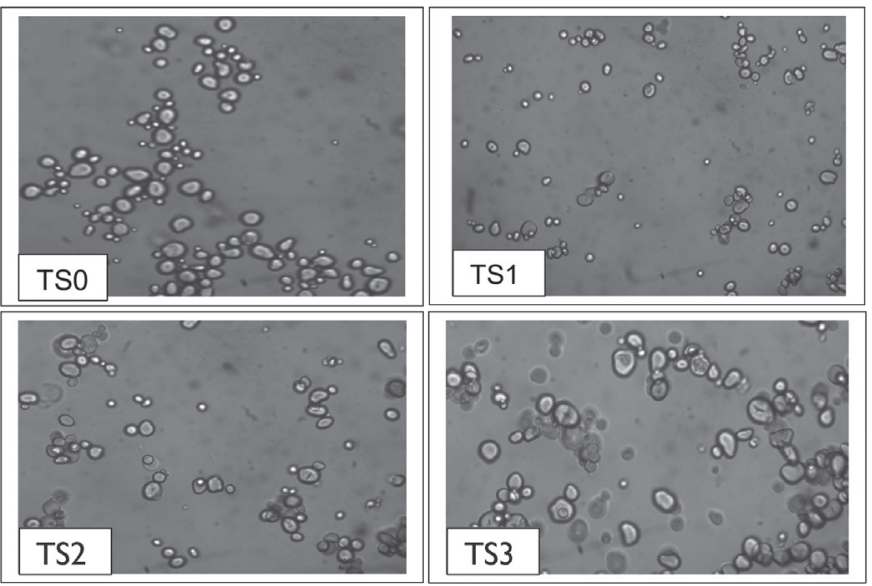

Figure 1. Photomicrograph of native Tigernut starch (TSO), crosslinked starches from day 5 (TS1), day 10 (TS2), and day 15 substrate (TS3) TS: Tigernut starch 
intensity in the $\mathrm{C}-\mathrm{H}$ stretch could be because of the possible change in starch's amylose and amylopectin content, which is known to be responsible for variation in the physicochemical properties of starch. All the starches showed peaks at about 1640,1338 , and $1140 \mathrm{~cm}^{-1}$, indicating the presence of intramolecular hydrogen bonds, $\mathrm{C}-\mathrm{H}$ bending, and $\mathrm{C}-\mathrm{O}$ stretching. Bands at 708-928 $\mathrm{cm}^{-1}$ portray the characteristic identity of the starch. ${ }^{50}$

\section{DSC of TS and its crosslinked derivatives}

Presented in Figure 3A-C are DSC thermograms of the behavior of the starch granules of all the samples (TS0, TS1, TS2, and TS3) when subjected to heat. A series of processes that occur when starch is heated and converted to paste is referred to as starch gelatinization; and the temperature at which gelatinization occurs is dependent on the starch molecules' crystalline nature. This transitional phase of starch granules is an important characteristic that makes them applicable in industrial processes.

Thermal properties of the native and modified starches are presented in Table 6 . The onset temperature of gelatinization ( $\mathrm{T}_{0}$ ) of TSO is observed to be lower $\left(60.35^{\circ} \mathrm{C}\right.$ ) than those of TS2 and TS3 $\left(104.16^{\circ} \mathrm{C}\right.$ and $113.18^{\circ} \mathrm{C}$, respectively). This is attributable to increased granule strength conferred as a result of crosslinking, thus higher temperature is required to initiate starch gelatinization. Increase in gelatinization temperature also indicates better binding ability of the starch, which shows that crosslinked starches possess better binding capability than native starch. Some studies have also reported an increase in gelatinization temperature with other crosslinked starches, relating to decreased mobility of amorphous chains in the starch granule. ${ }^{16,38}$ Similarly, peak $\left(T_{p}\right)$ temperature and conclusion temperature $\left(T_{c}\right)$ of the modified starches were observed to be generally higher than those of TSO $\left(125.59^{\circ} \mathrm{C}\right.$ and $134.44^{\circ} \mathrm{C}$, respectively). This suggests that modified starches acquire more crystalline forms than the native starch; this is in tandem with literature where positive correlation between onset and peak temperature of gelatinization and the materials' amorphous/crystalline nature have been reported. ${ }^{50,51}$

The enthalpy of gelatinization $(\Delta H)$ is directly related to the starch granules' crystalline nature (amylopectin), and demonstrates the extent to which the bond order within the

\begin{tabular}{|c|c|c|c|c|}
\hline Parameter & TSO & TS1 & TS2 & TS3 \\
\hline Onset temperature $\left({ }^{\circ} \mathrm{C}\right)$ & 60.35 & 59.84 & 104.16 & 113.18 \\
\hline Peak temperature $\left({ }^{\circ} \mathrm{C}\right)$ & 125.59 & 141.60 & 124.47 & 132.88 \\
\hline $\begin{array}{l}\text { Conclusion temperature } \\
\left({ }^{\circ} \mathrm{C}\right)\end{array}$ & 134.44 & 293.41 & 129.52 & 132.92 \\
\hline $\begin{array}{l}\text { Enthalpy of } \\
\text { gelatinization }\left[\mathrm{J} /\left(\mathrm{g}^{*} \mathrm{~K}\right)\right]\end{array}$ & 1926.95 & 2120.73 & 488.44 & 1096.20 \\
\hline$\Delta \mathrm{T}\left({ }^{\circ} \mathrm{C}\right)$ & 74.09 & 233.57 & 25.36 & 25.74 \\
\hline Peak height index $(\mathrm{PHI})$ & 26.01 & 9.07 & 19.26 & 42.59 \\
\hline
\end{tabular}

TS: Tigernut starch, $\Delta \mathrm{T}$ : Gelatinization temperature range
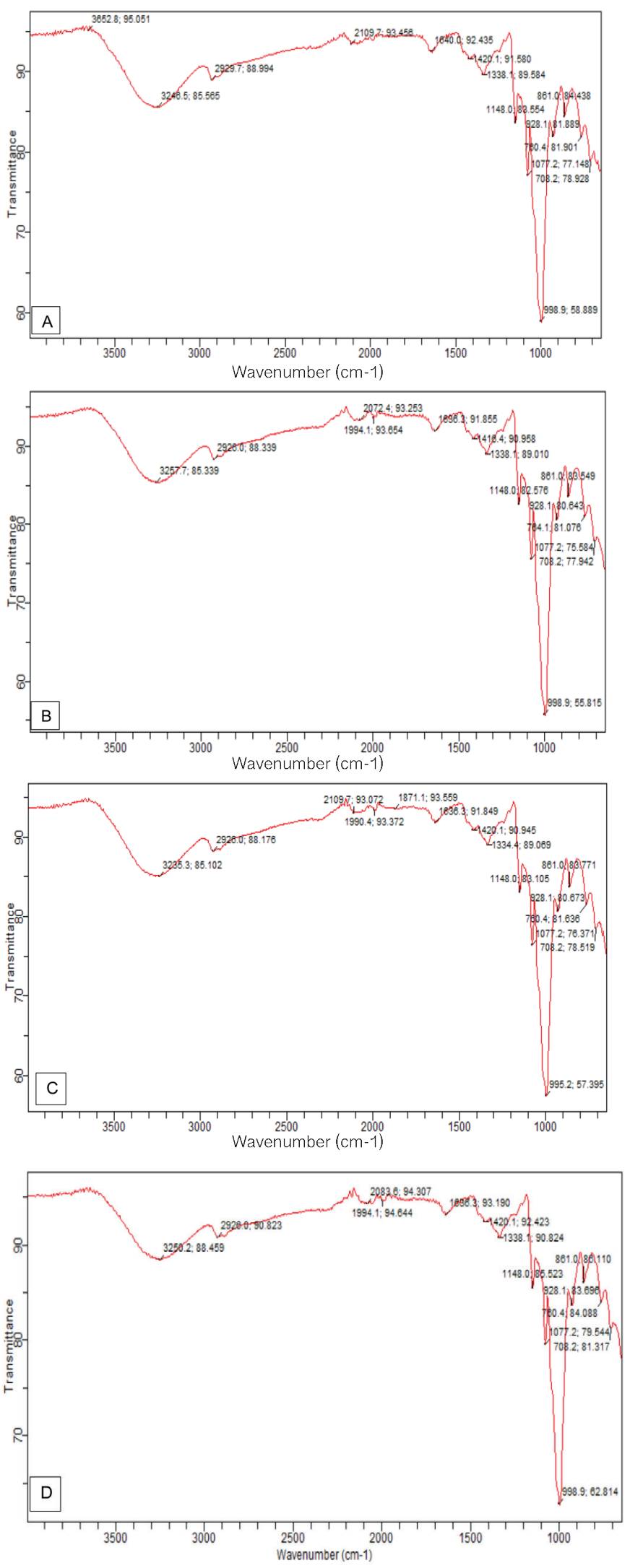

Figure 2. Fourier transform infrared (FTIR) spectra of (A) native Tigernut starch, (B) crosslinked starch from day 5 substrate, (C) crosslinked starch from day 10 substrate, (D) crosslinked starch from day 15 substrate 

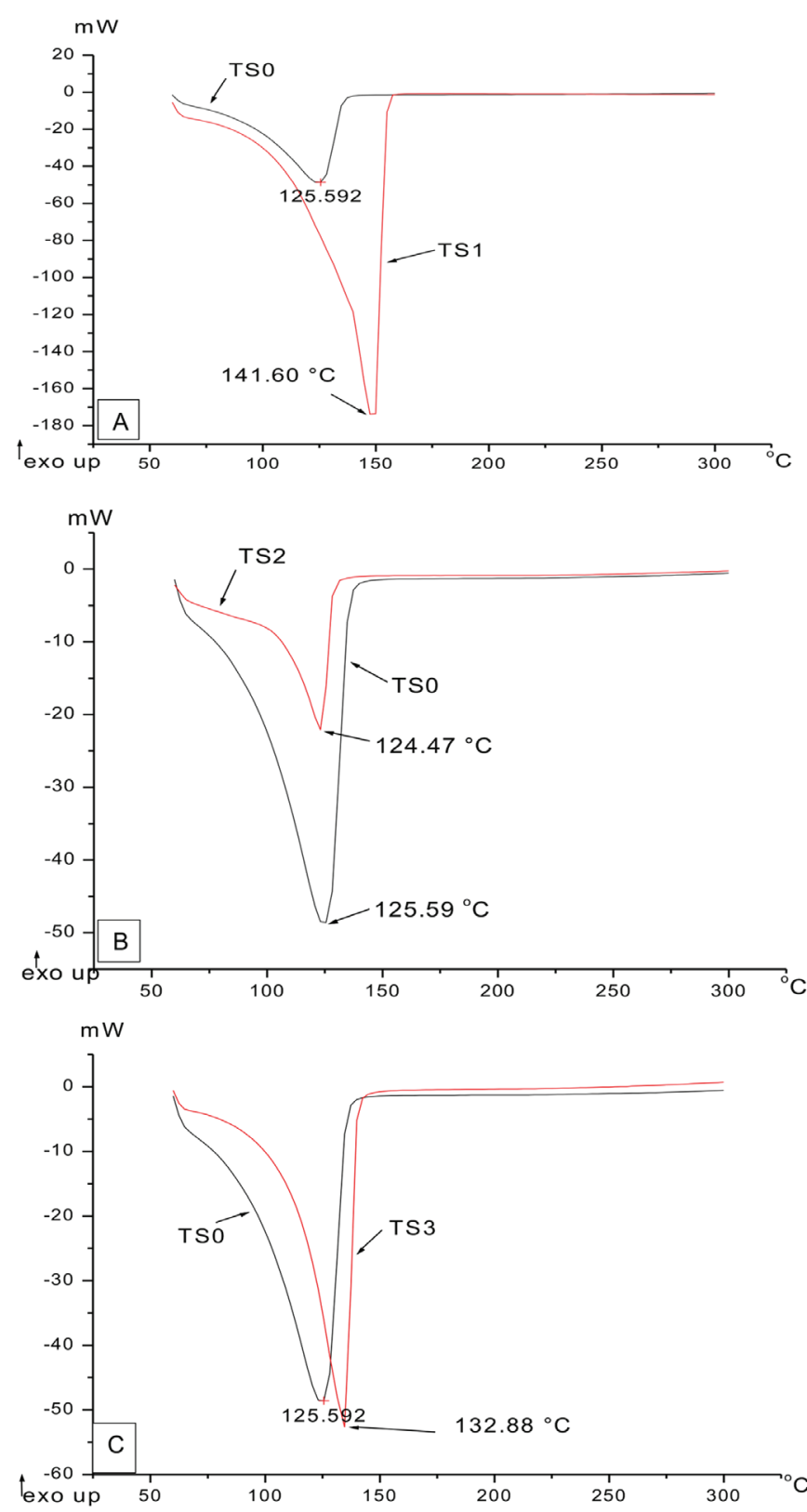

Figure 3. (A) Native Tigernut starch (TSO) and crosslinked starch from day 5 substrate (TS1); (B) TSO and crosslinked starch from day 10 substrate (TS2); (C) TS0 and crosslinked starch from day 15 substrate (TS3)

starch molecule is broken and melted during the heating process. Considered to be the result of dissimilar bond forces within the starch granules are the differences in $\Delta H^{52}$ Higher gelatinization enthalpies as observed with TSO and TS1, 1926.95 and $2120.73 \mathrm{~J} /\left(\mathrm{g}^{\star} \mathrm{K}\right)$, respectively, shows that higher energy is required to disentangle these bonds compared with those of TS2 and TS3; thus, showing the crosslinking effect on bond rearrangement within the starch granules. Therefore, TS1 would function as a better binder than TS2 and TS3.

Generally, higher $T_{o}, T_{p}$, and $T_{c}$ of the modified starches suggest high degree of crystalline association within those granules than in TSO; these resulted in higher structural stability and resistance to gelatinization as previously reported. ${ }^{53}$ Low temperatures observed in TSO could be an indication of low stability of starch molecules because of weak molecular arrangement, which corroborates with the theory that native starches are generally unable to withstand industrial temperatures.

Peak height index (PHI) is an indication of starch granules distribution and its uniformity during gelatinization. Table 6 shows a reduction in the peak height of TS1 and TS2 in relation to TSO, which could be attributed to the effect of increasing the concentration of the crosslinking substrate. $\mathrm{PHI}$ and $\Delta \mathrm{T}$ are observed to be negatively related; the wider the temperature range as a result of higher gelatinization temperature, the smaller the $\mathrm{PHI}$ as observed with TS1. This suggests that the modified starches could be effective as a binding agent in solid dosage formulations.

\section{CONCLUSION}

We proved in this study that agricultural waste constituting environmental nuisance, such as orange peels, could be employed as raw material for the green synthesis of starch obtained from $C$. esculentus tubers. Results obtained shows that modified TS had better water-holding capacity and thermal stability while retaining its microstructural properties, which suggests that it may perform well as binding agents in food and pharmaceutical industries.

\section{ACKNOWLEDGMENTS}

The authors are grateful to the technical staff of the Department of Pharmaceutical Technology and Raw Materials Development, NIPRD for their support during the course of this study.

Conflicts of interest: No conflict of interest was declared by the authors. The authors alone are responsible for the content and writing of the paper.

\section{REFERENCES}

1. Adebayo AS, Itiola OA. Effects of breadfruit and cocoyam starch mucilage binders on disintegration and dissolution behaviors of paracetamol tablet formulations. J Pharm Tech. 2003;80:78-90.

2. Manek RV, Builders PF, Kolling WM, Emeje M, Kunle OO. Physicochemical and binder properties of starch obtained from Cyperus esculentus. AAPS PharmSciTech. 2012;13:379-388.

3. Esezobo S, Ambujam V. An evaluation of starch obtained from plantain Musa paradisiaca as a binder and disintegrant for compressed tablets. J Pharm Pharmacol. 1982;34:761-765.

4. Muazu J, Musa H, Bhatia PG. Evaluation of the glidant property of Fonio starch. Res J App Sci Eng Tech. 2010;2:149-152.

5. Khunkitti W, Aromdee C, Vorarat S, Chitropas P. The potential of jackfruit starch for use as suspending agent and emulsifying agent. Songklanakarin J Sci Technol. 2006;8:145-155.

6. Onyishi IV, Chime SA, Kanu I. Application of Ipomea batatas starch as suspending agent in Acetaminophen suspension. Afr $J$ Pharm Pharmacol. 2014;8:24-30. 
7. Omojola M, Orishadipe AT, Afolayan M, Adebiyi AB. Preparation and physicochemical characterization of icacina starch citrate - a potential pharmaceutical/industrial starch. Agric Biol J N Am. 2012;3:11-16.

8. Alcázar-Alay CS, Meireles MAA. Physicochemical properties, modifications and applications of starches from different botanical sources. Food Sci Tech (Campinas). 2015;35:215-236.

9. Isah S, Oshodi AA, Atasie VN. Physicochemical properties of cross linked acha (Digitaria exilis) starch with citric acid. Chem Int. 2017;3:150157.

10. Tomasik P, Zaranyika MF. Nonconventional methods of modification of starch. Adv Carbohd Chem Biochem. 1995;51:243-318.

11. Rusli D, Azronnizan Q, Maaruf AG, Nik IND, Bohari MI. Hydroxypropylation and acetylation of sago starch. Malay J Chem. 2004;6:48-52.

12. Neelam K, Vijay S, Lalit S. Various techniques for the modification of starch and the applications of its derivatives. Int Res $\mathrm{J}$ Pharm. 2012;3:25-31.

13. Yadav BS, Guleria P, Yadav RB. Hydrothermal modification of Indian water chestnut starch: Influence of heat-moisture treatment and annealing on the physicochemical, gelatinization and pasting characteristics. LWT - Food Sci Tech (Campinas). 2013;53:211-217.

14. Abbas KA, Khalil SK, Hussin ASM. Modified starches and their usages in selected food products: A Review Study. J Agric Sci. 2010;2:90-100.

15. Maitra J, Shukla VK. Cross-linking in Hydrogels - A Review. Amer J Pol Sci. 2014;4:25-31.

16. Shah N, Mewada RK, Mehta T. Crosslinking of starch and its effect on viscosity behavior. Rev Chem Eng. 2016;32:265-270.

17. Singh J, Kaur L, McCarthy OJ. Factors influencing the physicochemical, morphological, thermal and rheological properties of some chemically modified starches for food applications: A Review. Food Hydrocoll. 2007;21:1-22.

18. Hirsch JB, Kokini JK. Understanding the mechanism of cross-linking agents (POCL3, STMP, and EPI) through swelling behavior and pasting properties of cross-linked waxy maize starches. Cereal Chem. 2002;79:102-107.

19. Wattanachanta S, Muhammad K, Hashimb DM, Rahmanb RA. Effect of crosslinking reagents and hydroxypropylation levels on dual-modified sago starch properties. Food Chem. 2003;80:463-471.

20. Yin L, Zhu Z. Research on the preparation of crosslinked starch chlorinated with sodium hypochlorite. Wuhan University J Nat Sci. 2003;8:861-865.

21. Chowdary KPR, Chaithanya KK. Preparation and evaluation of cross linked starch urea. A new polymer for controlled release of Aceclofenac. Asian J Chem. 2010;22:4265-4270.

22. Omojola MO, Manu N, Thomas SA. Effect of cross linking on the physicochemical properties of cola starch. Afr J Food Sci. 2012;6:91-95.

23. Torrado AM, Cortés S, Manuel Salgado J, Max B, Rodríguez N, Bibbins BP, Converti A, Manuel Domínguez J. Citric acid production from orange peel wastes by solid-state fermentation. Braz J Microbiol. 2011;42:394409.

24. Soccol CR, Vandenberghe LPS. Overview of applied solid state fermentation in Brazil. Biochem Eng J. 2013;13:205-218.

25. Balasundram N, Sundram K, Samman S. Phenolic compounds in plants and agri-industrial by-products: Antioxidant activity, occurrence, and potential uses. Food Chem. 2006;99:191-203.
26. Rabetafika HN, Bchir B, Blecker C, Richel A. Fractionation of apple by-products as source of new ingredients: Current situation and perspectives. Trends Food Sci Technol. 2014;40:99-114.

27. Dhandayuthapani K, Thiyageswaran G, Kumar R. Production of citric acid from banana waste by Aspergillus niger. Int J App Bioeng. 2008;2:13.

28. Vafina A, Proskurina V, Vorobiev V, Evtugin VG, Egkova G, Nikitina E. Physicochemical and morphological characterization of potato starch modified by bacterial amylases for food industry applications. J Chem. 2018;8:1-9.

29. Rohr M, Kubicek CP, Kominek J. Citric acid. In- Biotechnology, Reed, G. and Rehm, HJ. (Eds.), Verlag-Chemie, Weinheim; 1983:419-454.

30. Pandey A, Soccol CR. Bioconversion of biomass: A case study of lignocellulosics bioconversions in solid state fermentation. Brazilian Arch Biol Technol. 1998;41:379-390.

31. Kunle OO, Ibrahim YE, Emeje MO, Shada S, Kunle Y. Extraction and physicochemical compaction properties of Tacca starch- a Potential Pharmaceutical excipient. Starch/Stärke. 2003;55:319-325.

32. Adebiyi AB, Omojola MO, Orishadipe AT, Afolayan MO, Olalekan D. Tacca starch citrate - A potential pharmaceutical excipient. Arch. Appl. Sci. Res. 2011;3:114-121.

33. Kornblum SS, Stoopak SB. A new tablet disintegrating agent: Crosslinked polyvinylpyrrolidone. J Pharm Sci. 1973;62:43-49.

34. Yokoya F. Citric Acid Production. In: Industrial Fermentation Series, Campinas, SP, Brazil; 1992:1-82.

35. Mohammadi MS, Harnby N. Bulk density modelling as a means of typifying the microstructure and flow characteristics of cohesive powders. Powder Technol. 1997;92:1-8.

36. Kenneth A, Afolayan MO, Oberafo AA, Thomas S. Isolation and physicochemical characterization of Tigernut (Cyperus esculentus) starch as a potential industrial biomaterial. Int J Mat Sci App. 2014;3:3741.

37. Coursey DG, Rasper V. Properties of starches of some West African yams. J Sci Food Agric. 1967;18:240-248.

38. Akpa JG, Dagde KK. Modification of cassava starch for industrial uses. Int J Eng Tech. 2012;2:913-919.

39. Emeje M, Kaita R, Isimi C, Buragohain A, Kunle O, Ofoefule S. Synthesis, physicochemical characterization and functional properties of an esterified starch. Afr J Food Agric Nutr Dev. 2012;65:369-374.

40. Isah S. Chemical modification of grains starch for improved functionality. Int J Chem Mat Sci. 2018;1:6-16.

41. Mariod AA. Gum arabic: structure, properties, application and economics, London, United Kingdom: Elsevier Ltd. Academic Press; 2018.

42. Jyothi AN, Moorthy SN, Sreekumar JN, Rajasekharan KN. Studies on the properties of citrate derivatives of cassava (Manihot esculenta Crantz) starch synthesized by microwave technique. J Sci Food Agric. 2007;87:871-879.

43. British Pharmacopoeia (BP).Vol. I and II: Her Majesty's stationary office, university, press, Cambridge, London; 2002.

44. Adane M, Endale A, Bultosa G, Abdel-Mohsen MG, Gebre-Mariam T. Isolation and physicochemical characterization of Godare (Colocasia esculenta) starch from Ethiopia. Ethiop Pharm J. 2006;24:13-22. 
45. Emeje M, Isimi C, Kunle O. Effect of Grewia gum on the mechanical properties of paracetamol tablet formulations. Afr J Pharm Pharmacol. 2008:2:1-6.

46. Ohwoavworhua FO, Adelakun TA. Some physical characteristics of microcrystalline cellulose obtained from raw cotton of Cochlospermum planchonii. Trop J Pharm Res. 2005;4:501-507.

47. Loss PJ, Hood LF, Graham HD. Isolation and characterization of starch from Breadfruit. Cereal Chem. 1981;58:282-286.

48. Omojola MO, Akinkunmi YO, Olufunsho KO, Egharevba HO, Martins EO. Isolation and physicochemical characterization of Cola starch. Afr J Food Agric Nutr Dev. 2010;10:2884-2900.

49. Xie $X$, Liu $Q$. Development and physicochemical characterization of new resistant citrate starch from different corn starches. Starch/ Stärke. 2004:56:364-370.
50. Babu AS, Parimalavalli R, Jagannadham K, Rao JS. Chemical and structural properties of sweet potato starch treated with organic and inorganic acid. J Food Sci Technol. 2015;52:5745-5753.

51. Park IM, Ibanez AM, Zhong F, Shoemaker CF. Gelatinization and Pasting Properties of Waxy and Non-waxy Rice Starches. Starch/Stärke. 2007;59:388-396.

52. McPherson AE, Jane J. Comparison of waxy potato with other root and tuber starches. Carbohyd Polym. 1999;40:57-70.

53. Bhupender SK, Rajneesh B, Baljeet SY. Physicochemical, functional, thermal and pasting properties of starches isolated from pearl millet cultivars. Int Food Res J. 2013;20:1555-1561. 